\title{
Synthesis of Carbon Nanotubes from Polymer Waste
}

\author{
Gaukhar T. Smagulova ${ }^{1,2}$, Nurmakhan B. Yesbolov ${ }^{1,2}$, Bayan B. Kaidar ${ }^{1,2}$, Nataliya V. Vassilyeva ${ }^{1,2}$, \\ Nikolay G. Prikhodko1, Zulkhair A. Mansurov ${ }^{1,2}$ \\ ${ }^{1}$ Institute of combustion problems \\ Bogenbay batyr st., 172, Almaty, Kazakhstan \\ smagulova.gaukhar@gmail.com \\ ${ }^{2}$ al-Farabi Kazakh national university \\ Al-Farabi ave., 71, Almaty, Kazakhstan \\ zmansurov@kaznu.kz
}

\begin{abstract}
The paper represents investigation on the synthesis of carbon nanotubes by chemical vapor deposition. The products of thermal decomposition of polyethylene waste were used as source of carbon. The influence of the decomposition temperature of polyethylene on the carbon nanotubes synthesis was provided. Cenospheres, preliminarily impregnated with aqueous solutions of nickel and cobalt nitrates, were applied as catalysts for carbon nanotubes synthesis. It was determined that in the framework of research, the best results for CNTs production were achieved at polyethylene decomposition temperature of $450{ }^{\circ} \mathrm{C}$ with catalyst based on cenospheres impregnated with nickel and cobalt nitrate solutions.
\end{abstract}

Keywords: Polymer waste, Carbon nanotubes, Chemical vapor deposition.

\section{Introduction}

Synthetic polymers and products of their application are widely used in everyday life, technics, construction sector, automotive industry and so on. About $50 \%$ of the synthetic polymers are used for disposable applications: packaging, agricultural film and disposable consumer goods; $20-25 \%$ - for elements of the long-term infrastructure: pipes, insulating coatings and construction materials; 25-30\% - for long-term applications with intermediate service life: electronic goods, furniture, vehicles, etc. [1]. Among the various classes of polymer waste, the leading positions are occupied by polypropylene and polyethylene waste [2]. According to Conversio Market \& Strategy GmbH [3], a high level of polymer waste recycling in Europe could be observed in Sweden, Norway, Germany, Ireland, the Czech Republic and Spain, whilst in the rest of EU countries, the level of processing is within $20 \%$. Regarding developing countries, the level of processing rarely reaches $10 \%$.

Combining the problem of recycling polymer waste and nanotechnology development has led to the improvement of areas related to waste recycling for the synthesis of nanomaterials, including carbon nanotubes. Carbon nanotubes have the prospect of application for obtaining various types of composite materials [4], flexible heating elements [5] and various other practical applications. Many factors impact on the synthesis of carbon nanomaterials from polymer waste, in particular, polyethylene: polymer type, polymer decomposition temperature, deposition time, presence of catalysts, the atmosphere in which the synthesis is carried out, etc. In [6], the authors carried out a comprehensive study of the lowdensity polyethylene decomposition process in the temperature range of $300-800{ }^{\circ} \mathrm{C}$. The authors presented that main decomposition products are: ethylene, propylene, isobutylene, 1-hexene and heptane. Application of various types of catalysts demonstrated that, in the absence of catalysts, the main decomposition product is ethylene, with neutral $\mathrm{Al}_{2} \mathrm{O}_{3}$ and $\mathrm{SiO}_{2}$, the main decomposition products are ethylene and 1-hexene and, finally, in case of zeolite, the content of 1hexene exceeds the ethylene and other decomposition products.

In the article [7], the authors used three types of polyethylene as a carbon source to synthesize carbon nanomaterials using the CVD method with catalyst made of iron nanopowder in the temperature range of $550-1050{ }^{\circ} \mathrm{C}$ in $\mathrm{H}_{2}, \mathrm{~N}_{2}$, and Ar. Consequently, the authors discovered that high-density polyethylene allows to generate the maximum yield of carbon nanomaterial. Furthermore, it was shown that at $1050{ }^{\circ} \mathrm{C}$ comparatively higher amount of multi-walled carbon nanotubes (MWCNT) with an insignificant content of carbon nanospheres could be obtained. In [8], the authors used various types of polymer waste to synthesize carbon nanotubes: high-density polyethylene, polypropylene, etc. The decomposition temperature of polyethylene was $700{ }^{\circ} \mathrm{C}$; the synthesis time was 30 minutes. 


\section{Experimental part}

In present work household garbage (plastic bags) was used as an initial material. In the beginning the polyethylene waste was pre-crushed and subjected to cleaning. Cleaning was carried out by washing the crushed sample with hot water and surface-active substances. After washing, the samples were dried under normal conditions. At the end of the drying process, the crushed samples were melted without chemical degradation in a porcelain dish by heating at temperatures up to $130{ }^{\circ} \mathrm{C}$ in order to obtain compact samples of polyethylene which could be conveniently loaded in the reactor.

To investigate the decomposition process, a three-zone furnace with a quartz reactor was used. The inner diameter of the pipe is $6 \mathrm{~cm}$, length is $120.7 \mathrm{~cm}$. A study on the effect of temperature on the decomposition process of polyethylene was provided. The process of decomposition of polyethylene wastes in the temperature range from 200 to $450{ }^{\circ} \mathrm{C}$ was investigated as well. It was established experimentally that at $200{ }^{\circ} \mathrm{C}$ there is no thermal destruction of polyethylene waste and only slight sintering of the patterns could be observed. At a temperature of $300-350{ }^{\circ} \mathrm{C}$ a slight destruction of the sample occurs, however, this temperature is not enough for complete destruction of polyethylene waste. Thus, it was experimentally determined that at the temperature of $400-450{ }^{\circ} \mathrm{C}$, complete thermal destruction of the original polyethylene samples proceeds. Thermal decomposition of polyethylene waste occurs with release of white smoke with a specific smell. As a result, thermal decomposition of polyethylene without oxygen access resulted products, which subsequently were subjected to cold extraction for further IR analysis.

Synthesis of carbon nanotubes was performed by thermal destruction of polyethylene waste. Synthesis process was carried out in a three-zone furnace. In the first zone, a quartz cuvette with polyethylene samples with a mass of $4 \mathrm{~g}$ was installed, where the temperature was set at $400-450{ }^{\circ} \mathrm{C}$. Cenospheres $\left(\mathrm{P}^{\prime}{ }_{100 / 500}\right)$ were used as a catalyst basis for the synthesis of CNTs. Optical microscopy images of cenospheres are presented in Figure 1.

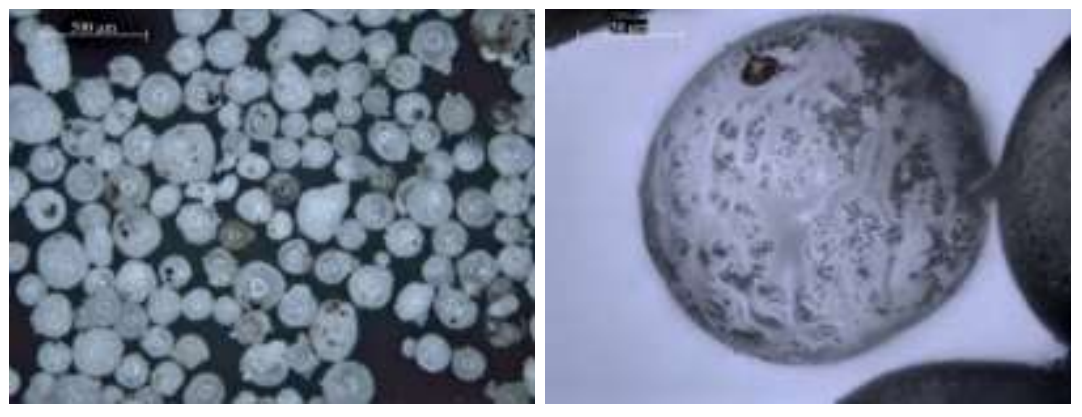

Fig. 1: Micrographs of cenospheres at different magnifications.

The cenospheres, which were used as the basis for the catalyst, are hollow spherical structures. Their sizes vary in the range from 100 to 500 microns. The composition of cenospheres: $\mathrm{SiO}_{2}-58-68 \%, \mathrm{Al}_{2} \mathrm{O}_{3}-32-38 \%, \mathrm{Fe}_{2} \mathrm{O}_{3}-1.4-2$ $\%, \mathrm{CaO}-1.9 \%, \mathrm{MgO}-1 \%, \mathrm{~K}_{2} \mathrm{O}+\mathrm{Na}_{2} \mathrm{O}$ - no more than $1.5 \%$. Cenospheres melting point is $1350-1500{ }^{\circ} \mathrm{C}$. The wall thickness of the microsphere diameter is 5-10\%.

In order to prepare the catalyst $10 \mathrm{~g}$ of cenospheres were impregnated with an aqueous solution of nickel nitrate, cobalt nitrate or their mixture with a concentration of $100 \mathrm{~g} / \mathrm{l}$. Next, the catalyst samples were dried at $70{ }^{\circ} \mathrm{C}$ for $2-3$ hours until complete removal of moisture. Quartz cuvettes with a catalyst weight of 1-2 g were installed in the third furnace zone. The temperature in the second and third zones of the furnace were set at 700 and $800{ }^{\circ} \mathrm{C}$, respectively. Nitrogen with a flow rate of $540 \mathrm{~cm}^{3} / \mathrm{min}$ was applied as a transport gas. Synthesis time was $30 \mathrm{~min}$. During the synthesis, nickel and cobalt nitrates had decomposed to form nickel and cobalt respectively.

\section{Result and discussion}

Figure 2 shows the SEM images of the sample obtained on the nickel/cobalt cenospheres at a decomposition temperature of polyethylene of $400{ }^{\circ} \mathrm{C}$. 

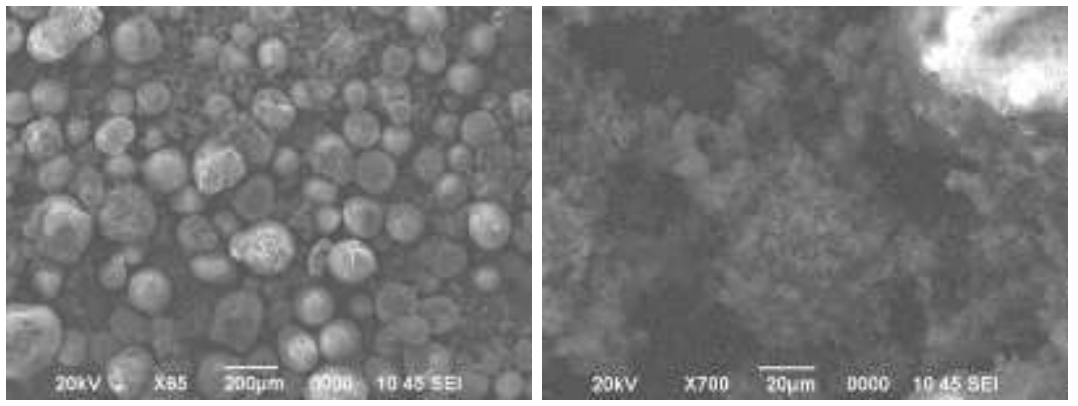

Fig. 2: A sample of carbon material on $\mathrm{Ni} / \mathrm{Co}$ catalyst at $400{ }^{\circ} \mathrm{C}$.

As could be seen from the SEM images carbon nanomaterial of amorphous structure was produced on the cenospheres surface. Thus, temperature of $400{ }^{\circ} \mathrm{C}$ is not enough for the synthesis of nanotubes.

Figure 3 shows the SEM images of the sample obtained on the cobalt cenospheres at a decomposition temperature of polyethylene of $450^{\circ} \mathrm{C}$.
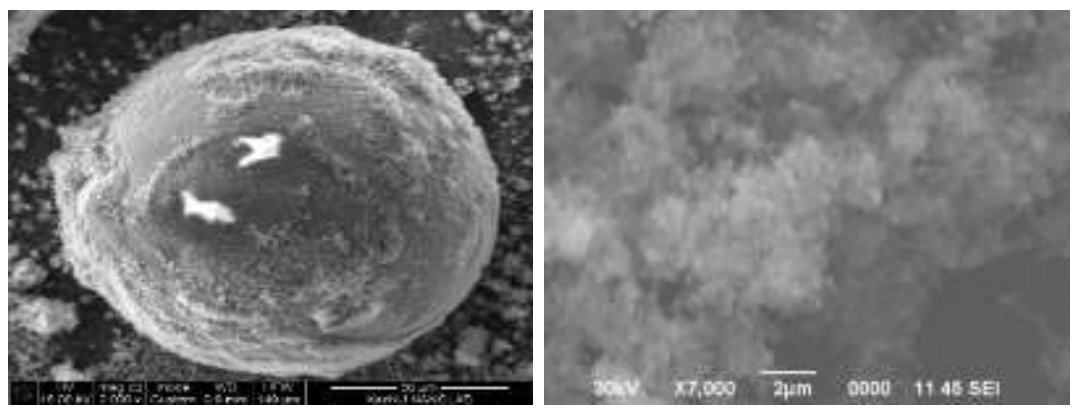

Fig. 3: A sample of carbon material on the Co catalyst at a temperature of $450{ }^{\circ} \mathrm{C}$.

As can be seen from the results of SEM analysis, due of the synthesis, cenospheres were coated with carbon nanomaterial, which mainly consists of an amorphous phase. Besides that, a small number of carbon nanotubes with a diameter of 60-70 nm could be observed.

Figure 4 represents SEM images of the sample obtained on nickel/cobalt cenospheres at polyethylene decomposition temperature of $450{ }^{\circ} \mathrm{C}$.

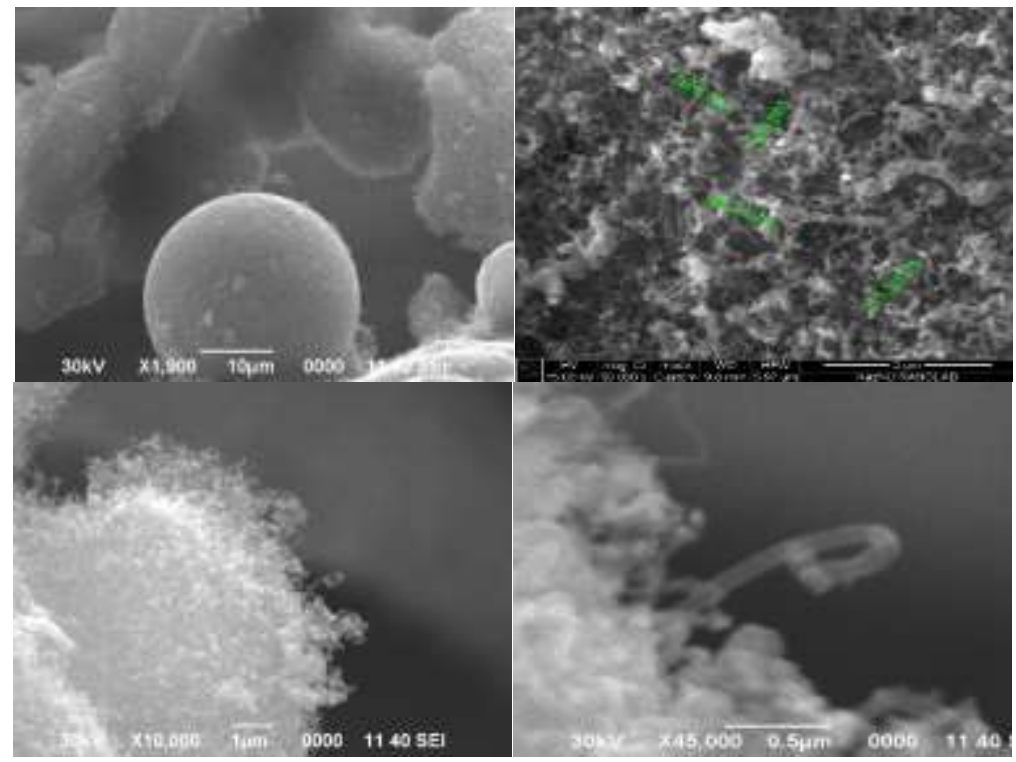

Fig. 4: A sample of carbon material on $\mathrm{Ni} / \mathrm{Co}$ catalyst at $450{ }^{\circ} \mathrm{C}$. 
It could be noticed from SEM images, that as a result, the surface of cenospheres is coated with carbon nanotubes with diameters from 40 to $100 \mathrm{~nm}$. Besides that, there are small inclusions of amorphous phase and one-dimensional nanostructures in the form of fibers with a diameter of $\sim 300 \mathrm{~nm}$.

\section{Conclusion}

The study of the effect of polymer waste decomposition on the synthesis of carbon nanotubes showed that the process of decomposition of polyethylene waste begins with a temperature of $400{ }^{\circ} \mathrm{C}$, but the optimum temperature for synthesis of carbon nanotubes is $450{ }^{\circ} \mathrm{C}$. During the synthesis process, Ni/Co catalysts based on cenospheres demonstrated the best catalytic activity. In that case, the content of amorphous phase impurities is minimal; the diameter of carbon nanotubes varies from 40 to $100 \mathrm{~nm}$.

\section{Acknowledgements}

The work was carried out within the framework of the project "Production of carbon nanotubes in a reactor with a fluidized catalyst bed and their use in electric power systems" (AP05135539) of grant foundation of the Committee of Science of the MES of RK. The authors are grateful to the team of the National Nanotechnology Laboratory of Open Type at the al-Farabi Kazakh National University for assistance in carrying out physicochemical characterization.

\section{References}

[1] J. Hopewell, R. Dvorak, and E. Kosior, "Plastics recycling: challenges and opportunities," Philos Trans R Soc Lond B Biol. Sci., vol. 364, no. 1526, pp. 2115-2126, 2009.

[2] "Plastics - the Facts 2017" [Online]. Available: https://www.plasticseurope.org/application/files/6315/4510/9658/Plastics_the_facts_2018_AF_web.pdf.

[3] "Plastics - the Facts 2017" [Online]. Available: https://www.plasticseurope.org/application/files/5715/1717/4180/Plastics_the_facts_2017_FINAL_for_website_ one_page.pdf

[4] F.R. Sultanov, S.S. Pei, M. Auyelkhankyzy, G. Smagulova, B.T. Lesbayev, Z.A. Mansurov., "Aerogels Based on Graphene Oxide with Addition of Carbon Nanotubes: Synthesis and Properties," Eurasian ChemicoTechnological Journal, vol. 16, pp. 265-269, 2014.

[5] G.T. Smagulova, S. Kim, N.G. Prikhodko, B.T. Lesbayev, A.V. Mironenko, A.A. Zakhidov, Z.A. Mansurov, "Smart electroconductive textile by catalytic deposition of carbon nanotubes onto glass cloth," International Journal of Self-Propagating High-Temperature Synthesis, vol. 25, no. 3, pp. 173-176, 2016.

[6] J. Nisar, M. Ali, I. A. Awan., "Catalytic thermal decomposition of polyethylene by pyrolysis gas chromatography," J. Chil. Chem. Soc., vol. 56, no. 2, pp. 653-655, 2011.

[7] P. Jagdale, M. Sharon, G. Kalita, N. M. Maldar, M. Sharon, "Carbon Nano Material Synthesis from Polyethylene by Chemical Vapour Deposition," Advances in Materials Physics and Chemistry, vol. 2, pp. 1-10, 2012.

[8] N. Borsodi, A. Szentes, N. Miskolczi, C. Wu, X. Liu, "Carbon nanotubes synthetized from gaseous products of waste polymer pyrolysis and their application," Journal of Analytical and Applied Pyrolysis, vol. 120, pp. 304$313,2016$. 